\title{
Exploring the Determinants of Perceived Irreplaceability in Online Community
}

\author{
Yongwei Jiang \\ School of Management, Jinan University, Guangzhou, China \\ Email:196669003@qq.com \\ Received 6 January 2016; accepted 19 February 2016; published 22 February 2016 \\ Copyright (C) 2016 by authors and Scientific Research Publishing Inc. \\ This work is licensed under the Creative Commons Attribution International License (CC BY). \\ http://creativecommons.org/licenses/by/4.0/ \\ (c) (i) Open Access
}

\begin{abstract}
With the rapid development of online community, it is a challenge for many community operators to retain existing users. By integrating perceived investment and perceived benefit that user achieves through online community usage, we propose a research model to investigate the determinants of perceived irreplaceability of online community users. Based on the data collected from 336 users of online community, we empirically test the proposed model. The results of structural equation modeling analysis indicate that personalization, learning and hedonic value jointly determine online users' perceived irreplaceability.
\end{abstract}

\section{Keywords}

Online Community, Perceived Irreplaceability, Perceived Investment, Perceived Benefit

\section{Introduction}

In recent years, online community has become an important part of daily life for many internet users. With the increasing number of online communities and low switching cost, it is a challenge for online community to maintain existing users. A user decides his participation based on the perception of investment and benefit of using an online community. If a user investes great amount of time and effort in an online community, he is more likely to continue participant in it. However, if he finds that this community cannot satisfy his needs, he can stop using it or switch to another online community which provides the same benefit. Therefore, maintaining existing users is essential for an online community's long term development [1]. According to marketing literatures, continued relationship will positively increase existing customers' identification with the organization [2] and will reduce the likelihood of switching [3]. Furthermore, according to network externalities theory, if an online community maintains a large number of existing users, it will attract more new users. However, not many online communities are successful in retaining their users, which leads to membership switching [4]. Conse- 
quently, it is important to understand why user continues using the same online community.

A number of studies have examined the affective factor that drives user continuance intention [5]. However, a limited number of studies have paid attention to the important role of perceived irreplaceability in online community. Perceived irreplaceability arises from the perception of benefit and investment of an online community usage [6]. The more user perceived irreplaceability, the more likely he will continue using an online community. Given the important of this concept in online community, relatively few studies explore the determinants of users' perceived irreplaceability comprehensively. To address this issue, this study investigates the antecedents of users' perceived irreplaceability in online community by examining the role of perceived investment and perceived benefit of online community usage. This research assumes that perceived investment (i.e. personalization, learning) and perceived benefit (i.e. hedonic value, utilitarian value) play a joint role in the development of perceived irreplaceability.

The remainder of this paper is organized as follows. In Section 2, we provide a literature review of related studies. The research model and hypotheses are proposed in Section 3. Then Section 4 describes the research methodology used in this study, followed by the results of data analysis in Section 5. Section 6 concludes this paper by discussing our findings.

\section{Theoretical Background}

\subsection{Perceived Irreplaceability}

Many terms have been used to describe psychological dependence of the customer-firm relationship. Such terms include customer dependence [7], perceived irreplaceability [6] and cognitive lock-in [8]. Despite of the inconsistencies of this term, a growing number of researcher view dependence as an important driver of user behaviors in an ongoing customer-firm relationships [7]. Among them, perceived irreplaceability in online community context is defined as an individual's perception of specific usage behavior due to the perceived values that cannot be replaced by other activities [6]. Perceived irreplaceability, categorized as an affective variable in the past studies, arises because of users' evaluation about the costs and benefits of staying with a firm. While many scholars have acknowledged the important role of perceived irreplaceability in users' participation in online community, few studies have dedicated to reveal to antecedents of it. The current study empirically examines the determinants of perceived irreplaceability from investment and benefit perspectives.

\subsection{Perceived Investment}

In the online community context, perceived investment refers to users' economic, social or psychological investments made during the community usage [9]. Personalization is a form of perceived investments in online community. Many online communities are currently offered to users in a highly personalized form. This personalized usage will accumulate many personal data which cannot be easily transferred to other online community [9]. In such a case, the overall costs of switching to another online community are relatively high. As a result, the customer may maintain the current relationship with the online community. Learning is another form of perceived investments in online community. User who took time and effort to learn the features, routines and procedures of the online community will learn some skills which is also not transferrable to other community [9]. Thus, learning may generate some kinds of switching cost for user to stay in the online community.

\subsection{Perceived Benefit}

Perceived benefit serves as an important factor of perceived irreplaceability in online community. From the marketing literature, customers become loyal to a firm as this firm offers some value, that is perceived benefit, to them. Hedonic value and utilitarian value are two different forms of perceived benefit. Previous studies had indicated that both hedonic and utilitarian value is strong determinants of customers' relationship maintenance intention [10]. Conceptually, hedonism value is related to fun and playfulness, characterized as pleasure, curiosity, fantasy and happiness. While utilitarianism value is related to task completion, characterized as achieving necessity [10].

\section{Research Model and Hypotheses}

Figure 1 depicts the research model that this study proposes for examination of the determinants of perceived 


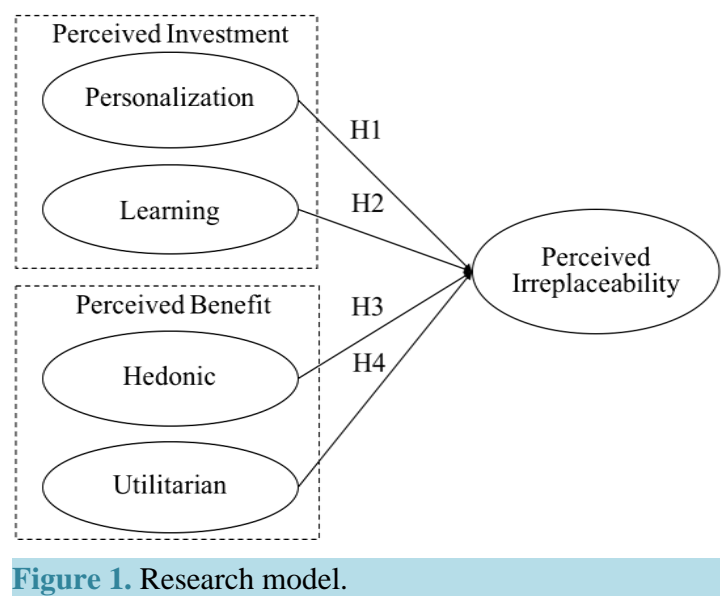

irreplaceability in the context of online community. As shown in Figure 1, we tend to explore the antecedents of perceived irreplaceability from the perspectives of perceived investment and perceived benefit. From the perspective of perceived investment, online community provides a number of technological features to modify their own needs. Likewise, the user's skill in using one online community is not necessarily transferrable to other community. As such, those who took time and effort to learn the features, routines and procedures of the online community are more likely to stay. From the perspective of perceived benefit, both hedonic value and utilitarian value are important factors to understand customer behaviors.

\subsection{Perceived Investment and Perceived Irreplaceability}

Prior studies have conceptualized personalization and learning as the specific investments that related to users' history of interaction with an online community [9]. These investments will generate some kinds of switch cost while user tends to switch to other online community. Personalization represents the transaction costs, and learning is associated with learning cost [9]. Accordingly, users who spent time and effort to modify the online community or learn the features, routines and procedures of the online community are more likely to realize that switch cost of changing the online community. Thus, it is reasonable to propose that in the context of online community, such investments as the extent of personalization and the extent of learning will be the basis for the formation of perceived irreplaceability. The above discussions lead to the following research propositions:

H1: Personalization is positively associated with perceived irreplaceability.

H2: Learning is positively associated with perceived irreplaceability.

\subsection{Perceived Benefit and Perceived Irreplaceability}

As discussed above, users are seeking both hedonic value and utilitarian value while using online community. Hedonic value is related to fun and playfulness, characterized as pleasure, curiosity, fantasy and happiness [10]. Users who received hedonic value from online community usage are likely to maintain their connection with the community. Utilitarian value is related to task completion, characterized as achieving necessity [10]. Those users who received utilitarian benefits from online community might increase their future using intentions. Therefore, when perceived enjoyable value in online community usage, users may be more likely to generate the feeling of perceived irreplaceability. The above discussions lead to the following research propositions:

H3: Hedonic value is positively associated with perceived irreplaceability.

H4: Utilitarian value is positively associated with perceived irreplaceability.

\section{Research Methodology}

\subsection{Measurement}

All of the tested scales used in our survey were adapted from the previous literatures. Specifically, the scales for perceived irreplaceability were adapted from Wang et al. (2015) [6]. These three items captured the unique values and benefits reviewed from online community usage behavior. To measure the perceived investment of on- 
line community usage, we used scales drawn from Kim and Son (2009) [9] to assess learning (three items) and personalization (four items) in online community. Additionally, measures for the perceived benefit of online community usage were adapted from Calder et al. (2009) [11]. These scales captured the perceived hedonic value (five items) and perceived utilitarian value (five items) of online community usage. All items were measured using a seven-point Likert scaleranging from "strongly disagree" to "strongly agree". Table 1 presents the descriptive statistics of the constructs.

\subsection{Sample and Data Collection}

The questionnaire was translated from English to Chinese and then back-translated from Chinese to English by certified professional translators to ensure the integrity of the constructs. Before deploying the main survey instrument, we invited 20 undergraduate students at a public university in China to conduct a pilot study in order to ensure that their understanding of the meaning of the items was consistent with the constructs being used in this study. Some minor modifications were made based on their feedbacks. The revised questionnaire was then used for the official online survey.

In order to assess the validation of the proposed model, we collected data from China online community user using an online survey. Instead of studying users of one or two online community, we targeted a broad set of online users who might have used many online communities. A self-reported survey was distributed to online community users. Only those who self-reposed as had used online community were eligible to participate in this study. The surveys asked respondents to consider an online community they recently visited. A total of 336 users completed the survey. The demographic details of these online community users are described in Table 2.

\begin{tabular}{ccc} 
Table 1. Descriptive statistics. & & \\
\hline Construct & Mean & SD \\
\hline Hedonic & 4.93 & 1.40 \\
Utilitarian & 5.06 & 1.23 \\
Personalization & 4.86 & 1.28 \\
Learning & 4.33 & 1.50 \\
Perceived Irreplaceability & 4.47 & 1.41 \\
\hline
\end{tabular}

Notes: All constructs are seven-point scales with the anchors 1 strongly disagree, 4 neutral and 7 strongly agree.

Table 2. Sample demographics.

\begin{tabular}{|c|c|c|c|c|c|}
\hline Dimension & Category & Percentage & Dimension & Category & Percentage \\
\hline \multirow{2}{*}{ Gender } & Male & $41.7 \%$ & \multirow{6}{*}{ Usage experience } & less than 6 month & $58.6 \%$ \\
\hline & Female & $58.3 \%$ & & 6 month to less than 1 years & $10.7 \%$ \\
\hline \multirow{4}{*}{ Age } & $<18$ & $2.4 \%$ & & & \\
\hline & $19-24$ & $53.9 \%$ & & 1 to less than 2 years & $14.3 \%$ \\
\hline & $25-30$ & $33.9 \%$ & & 2 to less than 3 years & $8.0 \%$ \\
\hline & $>31$ & $9.9 \%$ & & 3 or more years & $8.4 \%$ \\
\hline \multirow{5}{*}{ Education } & Senior high school & $3.9 \%$ & \multirow{7}{*}{$\begin{array}{l}\text { Duration of usage } \\
\text { per month }\end{array}$} & not once & $44.3 \%$ \\
\hline & Junior college & $11.3 \%$ & & once or twice in the last month & $23.2 \%$ \\
\hline & Bachelor’s degree & $55.1 \%$ & & once or twice a week & $16.7 \%$ \\
\hline & Master's degree & $26.8 \%$ & & $\begin{array}{l}\text { more than three } \\
\text { Times a week }\end{array}$ & $9.2 \%$ \\
\hline & Doctor's degree & $3.0 \%$ & & once or twice a day & $3.9 \%$ \\
\hline \multirow{2}{*}{ Occupation } & Student & $47.0 \%$ & & more than three & \multirow{2}{*}{$2.7 \%$} \\
\hline & Office worker & $53.0 \%$ & & Times a day & \\
\hline
\end{tabular}




\section{Data Analysis}

The structural equation modeling (SEM) was used to statistically test theoretical assumptions against empirical data. SEM is a multivariate technique that combines aspects of multiple regression and factor analysis to estimate a series of interrelated dependence relationships simultaneously [12]. Consequently, we conducted our main data analysis using an AMOS 17.0, which can test confirmatory measurement, goodness-of-fit, and common method bias.

A two-step approach was used for data analysis. We firstly assessed the measurement model and then tested the structural relationships among the latent constructs. We used the two-step approach in order to establish the reliability and validity of the measures before assessing the structural relationship of the model.

\subsection{Measurement Model}

Confirmatory factor analysis (CFA) was used to assess the measurement model. One item of hedonic value was dropped due to the low loading. All fit indices meet the commonly applied thresholds (see Table 3).

We further evaluated internal consistency, convergent validity, and discriminant validity by examining the Cronbach's alpha, composite reliability, and average variance extracted (AVE) of each construct (see Table 4). Internal reliability was examined by Cronbach's alpha and composite reliabilities (CR). The values of Cronbach's alpha and CR were higher than the criterion 0.70 [13], thereby justifying an adequate level of internal reliability. Convergent validity was used to ensure that theoretically related scales were highly correlated. Three criteria of convergent validity were proposed as a CR of more than 0.70, an AVE of 0.50 or above and item loadings higher than 0.70 [14]. As shown in Table 4, the CR of each construct ranges from 0.89 to 0.95 , the AVE ranges from 0.68 to 0.86 , and the item loadings are higher than 0.70 . All of these measures meet the recommended levels.

Discriminant validity indicates that the extent of the construct is low in correlation with other constructs. Such validity is demonstrated when the square root of AVE for the given construct is higher than the correlations between that construct and all other constructs [14]. As shown in Table 5, the square root of AVE exceeds the correlations between each construct and the other constructs, suggesting adequate discriminant validity for all constructs.

\subsection{Structural Model}

Following the establishment of the measurement model, we go forward to the structural model. The overall fit and the explanatory power of the proposed model were examined, and the results are shown in Table 6 and Figure 2. The overall goodness-of-fit (see Table 6) suggests a good fit between the structural model and the data.

Table 3. Fit indices of measurement model.

\begin{tabular}{ccc}
\hline Goodness of fit indices & Measurement model & Desired levels \\
\hline CMIN/DF & 2.20 & $<3.0$ \\
CFI & 0.97 & $>0.90$ \\
TLI & 0.97 & $>0.90$ \\
RMSEA & 0.060 & $<0.08$ \\
Standardized RMR & 0.036 & $<0.08$ \\
GFI & 0.91 & $>0.90$ \\
AGFI & 0.88 & $>0.80$ \\
No. of latent variables & 5 & \\
Total no. of items & 19 &
\end{tabular}

Note. CMIN = the minimum value of the discrepancy function; DF = degrees of freedom; CFI = comparative fit index; TLI = Tucker-Lewis index; RMSEA = root mean square error of approximation; RMR = root mean square residual; GFI = goodness-of-fit index; AGFI = adjusted GFI. 
Table 4. Confirmatory factor analysis.

\begin{tabular}{|c|c|c|c|c|c|}
\hline Latent construct & Indicator & Standard loading & Cronbach's alpha & CR & AVE \\
\hline Hedonic & $\begin{array}{l}\text { HD1 } \\
\text { HD2 } \\
\text { HD3 } \\
\text { HD4 }\end{array}$ & $\begin{array}{l}0.89^{* * *} \\
0.95^{\text {*** }} \\
0.87^{\text {*** }} \\
0.71^{\text {*** }}\end{array}$ & 0.91 & 0.92 & 0.74 \\
\hline Utilitarian & $\begin{array}{l}\text { UT1 } \\
\text { UT2 } \\
\text { UT3 } \\
\text { UT4 } \\
\text { UT5 }\end{array}$ & $\begin{array}{l}0.84^{* * *} \\
0.88^{* * *} \\
0.86^{* * *} \\
0.90^{\text {*** }} \\
0.84^{\text {*** }}\end{array}$ & 0.94 & 0.94 & 0.75 \\
\hline Personalization & $\begin{array}{l}\text { PS1 } \\
\text { PS2 } \\
\text { PS3 } \\
\text { PS4 }\end{array}$ & $\begin{array}{l}0.84^{\text {****}} \\
0.79^{\text {**** }} \\
0.80^{\text {*** }} \\
0.86^{\text {*** }}\end{array}$ & 0.89 & 0.89 & 0.68 \\
\hline Learning & $\begin{array}{l}\text { LN1 } \\
\text { LN2 } \\
\text { LN3 }\end{array}$ & $\begin{array}{l}0.88^{* * *} \\
0.89^{* * *} \\
0.90^{* * *}\end{array}$ & 0.92 & 0.92 & 0.79 \\
\hline Perceived Irreplaceability & $\begin{array}{l}\text { PI1 } \\
\text { PI2 } \\
\text { PI3 }\end{array}$ & $\begin{array}{l}0.93^{* * *} \\
0.94^{* * *} \\
0.91^{\text {*** }}\end{array}$ & 0.95 & 0.95 & 0.86 \\
\hline
\end{tabular}

Table 5. Discriminant validity.

\begin{tabular}{clllll}
\hline & HD & UT & PS & LN & \\
\hline Hedonic (HD) & $\mathbf{0 . 8 6}$ & & & \\
Utilitarian (UT) & 0.75 & $\mathbf{0 . 8 6}$ & & & \\
Personalization (PS) & 0.71 & 0.79 & $\mathbf{0 . 8 2}$ & & \\
Learning (LN) & 0.42 & 0.45 & 0.63 & 0.89 & $\mathbf{0 . 9 3}$ \\
Perceived Irreplaceability (PI) & 0.53 & 0.52 & 0.61 & 0.50 & \\
\hline
\end{tabular}

Table 6. Fit indices of structure model.

\begin{tabular}{ccc}
\hline Goodness of fit indices & Structure model & Desiredlevels \\
\hline CMIN/DF & 2.20 & $<3.0$ \\
CFI & 0.97 & $>0.90$ \\
TLI & 0.97 & $>0.90$ \\
RMSEA & 0.06 & $<0.08$ \\
Standardized RMR & 0.036 & $>0.08$ \\
GFI & 0.91 & $>0.90$ \\
AGFI & 0.88 & 50 \\
No. of latent variables & 5 & 19 \\
Total no. of items &
\end{tabular}

Note. CMIN = the minimum value of the discrepancy function; DF = degrees of freedom; CFI = comparative fit index; TLI = Tucker-Lewis index; RMSEA = root mean square error of approximation; RMR = root mean square residual; GFI = goodness-of-fit index; AGFI = adjusted GFI.

Figure 2 illustrates the path coefficients and explanatory power for the structural model. Three of the four proposed hypotheses were supported. Personalization ( $\mathrm{H} 1 ; \beta=0.31)$, learning $(\mathrm{H} 2 ; \beta=0.20)$ and hedonic value (H3; $\beta=0.20$ ) all had significant effects on perceived irreplaceability, explaining $41 \%$ of its variance. Contrary to our expectation, utilitarian value had no statistically significant effect on perceived irreplaceability (H4 was not supported). 


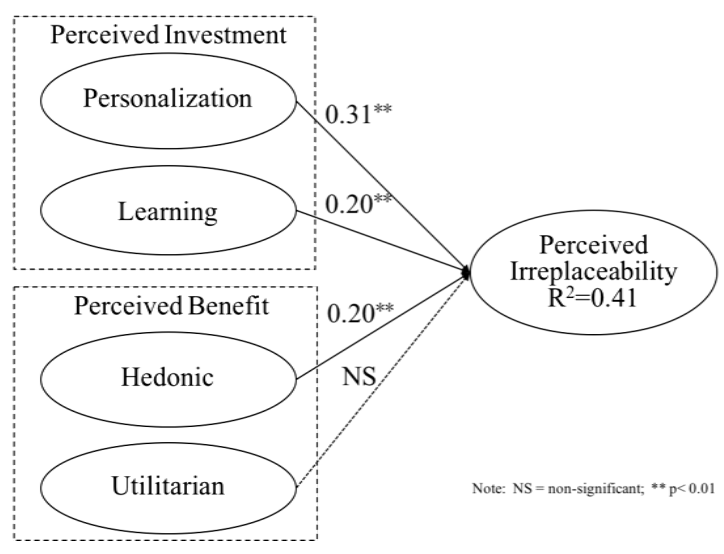

Figure 2. Structural equation model.

\section{Discussion}

This study aims to provide a research model to reveal the antecedents of perceived irreplaceability in online community. The results lend support to three of the four proposed links. Specifically, personalization, learning and hedonic value collectively explained $41 \%$ of the variance in perceived irreplaceability. Moreover, we found that personalization $(\beta=0.31)$ had a stronger power than learning $(\beta=0.20)$ and hedonic value $(\beta=0.20)$ in explaining perceived irreplaceability. The results indicated that users perceived irreplaceability of an online community based on investment and benefit reasons. We found that personalization and learning, serve as the perceived investment variables in this study, jointly informed users' perceived irreplaceability of online community. On the other hand, users perceived hedonic value, serve as the perceived benefit variables in this study, is significantly impact users' perceived irreplaceability of online community.

Contrary to our hypothesis, utilitarian value did not significantly impact users' perceived irreplaceability of online community. One explanation for the lack of support is that our data were collected from a broad set of online community users. Another explanation is that there are many online community providing the same service and user may be using many online communities with the similar type at the same time. If one community cannot provide the utilitarian value they need, they could easily switch to other community. As a result, utilitarian value is not significantly impact users' perceived irreplaceability of online community.

\subsection{Implications}

The present study created a research model for perceived irreplaceability in online community usage by combining perspectives of perceived investment and perceived benefit. Our research model has provided a good explanation of perceived irreplaceability in online community usage (41\%). We found that perceived investment (personalization, learning) and perceived hedonic value were significant determinants of perceived irreplaceability in online community usage. Our theoretical integration provides an important perspective for future studies of user retention in online community.

Our findings also indicated that perceived investment have stronger power than perceived benefit in determining perceived irreplaceability. Given the importance of perceived investment to the perceived irreplaceability of online community, interaction in online community should be strengthened to generate switching costs of online community users. From the perspective of online community operators, these results also suggest that involving user in online community activities must be taken into account beyond providing benefit to them. Therefore, online community operators must continuously explore design methods to improve the interaction aspects of online community usage.

\subsection{Limitation and Future Research}

This study has some limitations that should be noted. First of all, we collected data from a broad set of online users who might have used many online communities. However, online communities might differ in their key features. As a result, the research findings in this study might be difference in some specific online community. 
Future study can validate our research findings in one or two specific online community. Moreover, users' perceived irreplaceability of online community may not only come from perceived investment or perceived benefit from online community usage but also depend on their habits and satisfaction. Future research should examine online community users' habits and satisfaction in predicting their perceived irreplaceability.

\section{Conclusion}

In sum, this study provides empirical evidence to understand the users' perceived irreplaceability of online community. The research model integrates the perceived investment (i.e., personalization, learning) perspective and perceived benefit (i.e., hedonic value, utilitarian value) perspective. Personalization, learning and hedonic value together explain a large percentage (41\%) of the variance of users' perceived irreplaceability. Our results further suggest that for an online community, the perceptions of personalization are more important than learning and hedonic value in forming user dependence. As the aim of this study is to reveal the determinants of perceived irreplaceability in online community, we identify the importance of perceived investment and hedonic value in forming user dependent. We hope that this article can open up more research ideas on user maintenance in online community.

\section{References}

[1] Zheng, Y.M., Zhao, K. and Stylianou, A. (2013) The Impacts of Information Quality and System Quality on Users' Continuance Intention in Information-Exchange Virtual Communities: An Empirical Investigation. Decision Support Systems, 56, 513-524. http://dx.doi.org/10.1016/j.dss.2012.11.008

[2] Bhattacharya, C.B., Rao, H. and Glynn, M.A. (1995) Understanding the Bond of Identification: An Investigation of Its Correlates among Art Museum Members. The Journal of Marketing, 59, 46-57. http://dx.doi.org/10.2307/1252327

[3] Bhattacharya, C.B. (1998) When Customers Are Members: Customer Retention in Paid Membership Contexts. Journal of the Academy of Marketing Science, 26, 31-44. http://dx.doi.org/10.1177/0092070398261004

[4] Ma, M. and Agarwal, R. (2007) Through a Glass Darkly: Information Technology Design, Identity Verification, and Knowledge Contribution in Online Communities. Information Systems Research, 18, $42-67$. http://dx.doi.org/10.1287/isre.1070.0113

[5] Zhao, K., Stylianou, A.C. and Zheng, Y. (2013) Predicting Users' Continuance Intention in Virtual Communities: The Dual Intention-Formation Processes. Decision Support Systems, 55, 903-910. http://dx.doi.org/10.1016/j.dss.2012.12.026

[6] Wang, C., Lee, M.K.O. and Hua, Z. (2015) A Theory of Social Media Dependence: Evidence from Microblog Users. Decision Support Systems, 69, 40-49. http://dx.doi.org/10.1016/j.dss.2014.11.002

[7] Ashley, C., Noble, S.M., Donthu, N. and Lemon, K.N. (2011) Why Customers Won’t Relate: Obstacles to Relationship Marketing Engagement. Journal of Business Research, 64, 749-756. http://dx.doi.org/10.1016/j.jbusres.2010.07.006

[8] Johnson, E.J., Bellman, S. and Lohse, G.L. (2003) Cognitive Lock-In and the Power Law of Practice. Journal of Marketing, 67, 62-75. http://dx.doi.org/10.1509/jmkg.67.2.62.18615

[9] Kim, S.S. and Son, J.Y. (2009) Out of Dedication or Constraint? A Dual Model of Post-Adoption Phenomena and Its Empirical Test in the Context of Online Services. MIS Quarterly, 33, 49-70.

[10] Scarpi, D. (2012) Work and Fun on the Internet: The Effects of Utilitarianism and Hedonism Online. Journal of Interactive Marketing, 26, 53-67. http://dx.doi.org/10.1016/j.intmar.2011.08.001

[11] Calder, B.J., Malthouse, E.C. and Schaedel, U. (2009) An Experimental Study of the Relationship between Online Engagement and Advertising Effectiveness. Journal of Interactive Marketing, 23, 321-331. http://dx.doi.org/10.1016/j.intmar.2009.07.002

[12] Hair, J.F., Anderson, R.E., Tatham, R.L. and Black, W.C. (1998) Multivariate Data Analysis. Prentice Hall, New York.

[13] Nunnally, J.C. and Bernstein, I.H. (1994) Psychometric Theory. 3rd Edition, McGraw-Hill, New York.

[14] Fornell, C. and Larcker, D.F. (1981) Evaluating Structural Equation Models with Unobservable Variables and Measurement Error. Journal of Marketing Research, 18, 39-50. http://dx.doi.org/10.2307/3151312 